Rizvi, F.S. and Somachandra, W.D.I.V., 2019. Client's contribution to achieve sustainability through corporate social responsibility in the Sri Lankan construction industry. In: Sandanayake, Y.G., Gunatilake, S. and Waidyasekara, A. (eds). Proceedings of the $8^{\text {th }}$ World Construction Symposium, Colombo, Sri Lanka, 8-10 November 2019, pp. 168-178. DOI: doi.org/10.31705/WCS.2019.17. Available at: https://2019.ciobwcs.com/papers

\title{
CLIENT'S CONTRIBUTION TO ACHIEVE SUSTAINABILITY THROUGH CORPORATE SOCIAL RESPONSIBILITY IN THE SRI LANKAN CONSTRUCTION INDUSTRY
}

\author{
F.S. Rizvi ${ }^{1}$ and W.D.I.V. Somachandra ${ }^{2}$
}

\begin{abstract}
The Sri Lankan construction industry's impact on the environment, social and economy is inevitable; emphasising the need to adopt sustainability. Sustainability is distinguished in order to avoid depletion of natural resources as well as to maintain the ecological balance. Sustainability could result in a corporate level, based on construction business organisations further illustrating the concept of corporate social responsibility (CSR). CSR focuses on impact by organisations concerning the triple bottom line. CSR is identified as a path to achieve corporate sustainability. Stakeholders' participation is crucial to incorporate in a sustainable development plan which facilitates the identification of the clients who play a prominent role. This research followed a qualitative study by interviewing clients selected through snowball sampling in the Sri Lankan construction industry. Phenomenology was the approach followed for this research and bracketing was used as a method of analysis. Results of the research identified categories to achieve sustainability through CSR in the perception of clients as: cost constraint, government regulatory approach, consultants' intervention, client's apprehension on sustainability and their attitude on social and environmental aspects, thereby paving the path to develop recommendations.
\end{abstract}

Keywords: Client; Construction Industry; Corporate Social Responsibility (CSR); Sustainability; Sri Lanka.

\section{INTRODUCTION}

The construction industry develops physical assets that are man-made capitals (Spence and Mulligan, 1995). Clients, architects, engineering consultants, contractors and suppliers conduct construction businesses (Shen et al., 2010); that delivers services and supplies resources for the construction industry. Construction businesses involve stakeholders referred to as constituents (Kakabadse et al., 2005). Nevertheless, the construction industry is renowned for destructing the environment, negatively impacting communities, exploiting workers, natural resources, corrupt practices, and failure in health and safety measures (Huang and Lien, 2012; Murray and Dainty, 2009; Spence and Mulligan, 1995). Respectively, Barthorpe (2010) accuses the construction industry for having little concern towards the environment, for being thoughtless and

\footnotetext{
${ }^{1}$ Computing, Engineering and the Built Environment, Birmingham City University, Sri Lanka, salmahrizvi13@gmail.com

${ }^{2}$ Faculty of Construction and Engineering, International College of Business and Technology, Sri Lanka, vathsala@icbtcampus.edu.lk
} 
unsympathetic towards the society and for provoking its clients. The Sri Lankan construction industry is ranked as the fourth highest sector contributing to the economy (De Silva et al., 2008). Further, the Department of Census and Statistics of Sri Lanka (2017) represented the construction industry to be securing the fourth place for its employment population; creating an impact on the social perspective by generating opportunities for the labour force. Moreover, concerning the environmental perspective in Sri Lanka, the construction industry is yet to address the burdens caused by construction materials consumed for building construction (Abeysundara et al., 2009).

Therefore, as discussed above, the Sri Lankan construction industry impacts on the environment, social and economy indicating an interwoven relationship approaching to the concept of sustainability. Berger et al. (2007) describes the integration of environmental, economic and social concerns to an organisation's operations, strategy, decision-making and culture by referring to the term 'corporate social responsibility' (CSR). Furthermore, although O'Connor et al. (2015) stated that stakeholders including the clients are concerned about sustainability, Serpell et al., (2012) conversely concluded that engineers and architects were the most aware on sustainability whereas owners (client) and developers were not as conscious. However, as clients play a central role in the construction industry (Khalfan et al., 2005), they should demand for improved performance from construction industry players (Ling et al., 2005). From the majority viewpoint, "client is the key driver towards sustainable construction"; however, a doubt arises if the clients 'know enough to brief effectively'; quotes Pitt et al. (2009). Thus, there remains a challenge to examine the gap between the client's extent of awareness and incentives towards achieving sustainability through CSR in the Sri Lankan construction industry.

This research aims to examine the client's contribution towards attaining sustainability through CSR in the Sri Lankan construction industry. The paper first goes on to identify the concept of sustainability and its' relationship with CSR. It then identifies the clients' responsibility to achieve sustainability in the construction industry and analyses the Sri Lankan client's contribution to promote CSR. Finally, concluding and providing recommendations to improve client's influence to achieve sustainability through CSR in the Sri Lankan construction industry.

\section{LITERATURE REVIEW}

As indicated in the introduction, the construction industry significantly impacts on the environment, social and economy; highlighting the prominence to adopt sustainability. Sustainability is implied by the ability of an organisation to operate while maintaining a harmonious balance between the economic, social and environmental values (Herremans and Reid, 2002). Organisations pursue sustainability with the aim of enhancing business value (Presley and Meade, 2010). Corporate is defined as a group of organisations or business entities. Considering the terms; Dyllick and Hockerts (2002) distinguishes corporate sustainability as the ability of organisations to meet the needs of their direct and indirect stakeholders, without compromising on the needs of prospective stakeholders; aiming for this goal, organisations should effectively contribute to sustainability in the political domain while growing and maintaining their environmental, social, and economic capital base. 
The concept of CSR in business operations emerged and was universally acknowledged as "a path to achieve corporate sustainability" (Somachandra, 2016). CSR is a concept in which a business organisation is responsible for the influence of its corporate activities concerning the interaction with stakeholders and the environment (Murray and Dainty, 2009). Additionally, Carroll (1991) identifies philanthropic, ethical, legal and economic responsibilities in a pyramid forming CSR. Furthermore, Jones et al. (2006) debate as to whether organizations implementing CSR do so as a philanthropic gesture as opposed to applying it to the core business process. However, pursuing CSR is critical to achieve sustainable construction (Shen et al., 2010). Ebner and Baumgartner (2006) explain that CSR is the social dimension of sustainable development; on the other hand, the authors further cite that sustainable development is a source for CSR. CSR is identified as sustainable development in a corporate level while it maintains a strong relationship between the concepts possessing significant interdependencies. Accordingly, it is acknowledged that sustainability should be implemented in the business process, which derives corporate sustainability, being used as a path leading to the concept of CSR. Instigating the CSR concept in an extended corporate level will subsequently inherit corporate sustainability and contribute to related construction practices, which along with corporate sustainability will eventually lead to sustenance in the construction industry (Ebner and Baumgartner, 2006).

Stakeholder participation is a critical factor to be incorporated in the sustainable development plan where they would be in a position to influence an organisation's operations, objectives, progress and persistence (Bal et al., 2013). The client is the sole initiator who engages in a project from the inception to the completion stage (Zhao et al., 2012). Hence, the prominence of clients in the construction industry could not be exaggerated (Kometa et al., 1994). Client should precisely specify and define the objectives of projects as it could contribute as a base to assess project performance (Lim and Ling, 2002). This implies the prominent role entrusted to a client in terms of their contribution. The commitment of the client to the project priorities are namely; establishing the budget, formulating schedules and technical performance milestones, which are identified as project management characteristics related to distinguished success (Lim and Ling, 2002). Further, the authors argued that it is the clients' responsibility to make a reasonable effort in clearly defining and devising the project. Moreover, it was argued that generally project teams are prone to commence developing the project with the assumption that the client has already acknowledged the specific objectives and the most effective ways to achieve them. In such instances, authors infer that it is the clients' responsibility to make an effort to determine concerns rather than the project team making the clients aware. However, Pitt et al. (2009) questioned the client awareness to brief effectively in driving towards sustainability. Thus, making an effort to enhance consciousness is essential in order to eliminate the perception of financial decision-making, which will have the knock on effect of minimising the impact on the environment, social and economy by clients. Effective involvement of stakeholders including clients, who engage by extending and sharing their support and participating cohesively, will significantly affect the planning and development of innovative business solutions. Moreover, Ayuso et al. (2011) discovered that the knowledge obtained by the involvement of stakeholders has a co-relation to an organisation's sustainable orientation. The client plays a primary role of encouraging the implementation of sustainable construction performances (Serpell et al., 2012). Lim and Ling (2002) cited that generally clients have seven primary needs in the construction industry, which are maintenance 
cost, flexibility, time, function, economy, safety and quality. However, it is disappointing to discern that the client needs did not factor the provisions for the environmental impact and a reflection of the social setting, which are substantial components towards attaining sustainability. Encouraging clients to adopt sustainability by introducing incentives, gathering and promoting proof of the business case, using fiscal and regulatory framework and encouraging companies to promote sustainability driven performances are best practices to promote sustainability according to Pitt et al. (2009). Furthermore, the researchers recognised the client as the most important individual to define sustainable construction practices while ranking the architects as the second most important variable. Hence, this examination focuses on the clients' contribution to achieve sustainability through the path of CSR in the Sri Lankan construction industry.

\section{METHODOLOGY}

Collecting data for the research commences once the research problem is identified, aim and objectives are defined (Doody and Bailey, 2016; Kothari, 2004). Primary and secondary data are two types of data. Primary data is original data that is collected and secondary data is information that has already been processed (Kothari, 2004). This research is designated by achieving initial objectives through the literature review, which focussed on collecting secondary data. In addition, the final two objectives were achieved through primary data. Dörnyei (2007) categorizes three ways to collect primary data, which are qualitative, quantitative, and a mix-method. Qualitative data deals with nonnumerical data that explore and define the nature, and quality of how people understand, react and experience (Alshenqeeti, 2014), this justifies that a qualitative approach is appropriate for this research. The reason for selecting an approach of this nature arises as the final two objectives focuses on the perspective of Sri Lankan clients and as this research requires an inspectional and investigative study.

Among five qualitative designs identified by Creswell et al., (2007) phenomenology is best suited to this research as the author discusses characteristics, which correspond with this research. One such identified characteristic applicable in the research context is disciplined background focusing on understanding the experience of a respondent about a phenomenon. This research design is followed for this study as it focused on extracting what clients have in common subjected to them experiencing a phenomenon (Creswell et al., 2007). Moreover, Dörnyei (2007) exclaims; qualitative data are typically gathered conducting interviews and questionnaires. However, interviews are identified as a powerful source that would elicit the data narrated. This enables a researcher to analyse in great depth concerning the public view by investigation (Dörnyei, 2007). Thus, interviews were adopted as a strategy of inquiry to understand, investigate and identify the clients' current practice and view on adopting business process related CSR in the Sri Lankan construction industry. Polkinghorne (1989) evaluated that the recommended sample size to interview for phenomenology is 5 to 25 participants in a similar experience background. Thus, thirteen clients from the Sri Lankan construction industry involved in building construction were selected based on snowball sampling for this research and were allocated reference codes as 'INT' with a specific number assigned to each client. When considering the nature of the projects that clients were involved in, nearly $54 \%$ of same were developing commercial buildings, $31 \%$ were into residential building and the remainder were involved in a development mix. In addition, bracketing was used as an analysis method for this research as, bracketing is the process of recognizing a 
phenomenon followed by data collection from individuals who experience the phenomenon, further analysing the data and extracting the most significant quotes which then leads to classifying same into themes (Creswell et al., 2007; Lester, 1999).

\section{RESULTS AND DISCUSSION}

This research mainly focuses on clients' practices in the business process related to CSR. Results of this research indicated many classifications of the clients' contribution to promote CSR in the business process to facilitate sustainability; extracted through the interviews conducted to review the client's practices in-order to achieve sustainability through the fundamentals of CSR. Subsequently, five major categories were recognised, that are also identified as factors affecting the client to achieve sustainability in the construction industry through CSR. Such extracted categories are discussed below as referenced from the clients themselves.

\subsection{COST CONSTRAINT}

Cost is one of the most significant constraints identified by the results of this research. Cost could further be classified as initial cost concern, cost consciousness and economical. All respondents explicitly stated that their main concern was the cost, even though they are aware of sustainability-oriented benefits. INT-10 respondent exclaimed, "Trying to maintain sustainability but focusing on initial cost".

This clearly reveals the primary concern of a client. All clients explicitly stated that cost is their main concern, as their primary objective is to gain profit and were not willing to wait for the payback period. Furthermore, respondent INT-12 stated: "What happened is, it's still not that much of economical know (sustainability), still it's the cost". Further to that, INT-11 claimed that: "Environmentally friendly option was considered but we saw the cost to be economised and we mainly followed the UDA Concept".

It is not always about reducing the cost, but it rather reflects clients' knowledge and understanding mainly acquired through experience. Respondent INT-11 who occupies the building, viewed cost to be economised during construction phase but overlooked the operational phase in this regard. This reveals a lack of integrity between phases when making decisions by being cost conscious. Moreover, according to INT-5: "As middle rise property developers, we are a little afraid with regards to the initial cost. Otherwise we are ready to implement (Sustainability)".

This clarifies that initial cost is the prime point for residential property developers, further illustrating the fear to implement it, as they may not receive an anticipated profit level. The cost constraint category verifies the impact created on client perspectives.

\subsection{GOVERNMENT Regulatory APPROACH}

The second vital category is the government's regulatory approach. While conducting interviews, it was clearly identified from the sample that most of the clients' main objective is to acquire government approval, which seemed to be the only reason to adopt sustainable measures. When inquired whether the consultants introduced sustainable measures; INT-2 confessed that:

"Yeah actually, now; environmental thing of-course they discussed because we have to get the approval from ministry of environment \& according to the UDA approval. So, all those things have to be taken into consideration". 
This implies the significance of a regulatory approach in a client's mindset as further stated by INT-12; "Generally, we stick to the regulations. Whatever regulations enforced by the Government". Hence, government regulations reveal the effect on a client's approach to implement sustainable measures or which gives an extra mile of motivation to follow such concepts.

\subsection{CONSULTANTS' INTERVENTION}

Clients appoint a specialised agent as, engineering consultant or architects for supervision and monitoring of the construction work effectively on their behalf as majority of clients do not have confidence that the outcome will meet all expected specifications, and adhere to quality standards in the construction industry (Reve and Levitt, 1984). Although this is the case, some interviewees seem to feel that some consultants presently do not fulfil their obligations towards clients with respondent INT-9 exclaiming:

"The architect comes to site only once. During the beginning of the project they always come and try to impress us (client). But, after that they send juniors who have no idea. We have to call them and go behind them. It is very difficult to work with them".

Moreover, it was understood that the consultants were not approaching with sufficient information to convince the client to implement the sustainable concepts according to INT-11:

"If someone can show with facts and figures the benefit of using such concepts then it's easy to make a decision. There is a huge problem in convincing. Can do marketing but it's not practical. Say if we think we do a green concept building, we have to consider the maintenance; the practical issues are a concern in a country like Sri Lanka. There is no proper discipline; for a simple example, people do not even segregate the garbage properly. The consultants support is very important, but the contractor's workmanship is also important".

Furthermore, the interviewee INT-3 stated that:

"Most of his (Consultants) suggestions were attached mostly with architectural view but also energy saving and sometimes, energy saving when you see the cost then economical, but mostly architectural view I can say 60-70\%. Because, they (architects) want to develop their image. He doesn't care about the cost frankly saying".

This emphasises the huge gap in the interpersonal relationship between the clients and consultants sourced by communication and management constraints, extent of persuasiveness on encouraging the client to adopt good approaches for the project and poor collaboration, instead focusing on their personal intent. Through the sample, it was understood that the consultants mainly focus on aesthetic aspects and not catering to the benefit of the clients although they are hired for it.

\subsection{CLIENTS' APPREHENSION ON SUSTAINABILITY}

Almost all clients in the sample accepted that they were aware on benefits of sustainability concept. Nevertheless, according to INT-12, residential building developers who intended to sell units of their development viewed implementation of sustainability, as a constraint to obtain profit as earning profit was their main objective. This further implied a lack of social concern, as they did not consider on intergenerational relationship.

"Since our target is to sell; we are planning to sell know, so our prime target is the cost and to complete the job. Not sustainability. (What do you think about the green concept? 
Any involvement, interest or idea?) (Smiling sarcastically) for the time being No. for the project I don't think it's possible; with the project and cost. (What are the reasons you see it's not possible) suppose if we are using... basic example solar. That cost will directly go to the buyers know, so with the competitive environment you can't be in the market. That is the thing."

However, another responded recognised as INT-13 saw sustainability as a marketing tool.

“...So let's say we design a sustainable building, so called green building so we can, as a developer use it as a marketing tool you know. In the long run it will be beneficial to the occupants. So in that case we can use it as a marketing tool".

According to INT-12 and INT-13 respondents' quotes, it signifies the influence a client's viewpoint could lead to promoting CSR in order to achieve sustainability while still fulfilling their objectives. Therefore, the client's perception on sustainability creates a benchmark on contributing to promote CSR.

\subsection{Client Attitude on Social ANd Environmental ASPECTS}

Client inconsiderateness and ignorance portrays a negative attitude towards the social and environmental concerns. The social aspect was identified by inquiring their thoughts on labourers working at their site while the environmental factor was assessed by inquiring on measures taken to preserve a balance between the construction and environment with regard to waste management, noise pollution and gas emission. Correspondingly, INT-8 declares:

"Instructions were given to follow safety standard. I go and look in and see as if anything happens to the workers the company name will be ruined. They need only money; No education".

Sadly, this is the attitude of some clients towards social. Further, INT-12 states:

"To be honest we don't have enough skilled labours in Sri Lanka. I think the main issue is all the guys are driving tuk tuks now, so we have a huge problem with skilled labourers.... All together, we have about 400 labourers. Out of them 60 are foreign labours. The contractor will provide accommodation, food, and stuff. We don't get involved and look in that".

The statement of this respondent enlightens social concern as well as the economical concern, as employing foreign labourers will eventually affect the economy of the country. However, as clients do not look into the wellbeing of their labourers and their attitude in this regard, it could influence the decrease in the quota of local labourers.

With respect to the environmental consideration, INT-2 pronounces that:

"Waste of course at the moment they are...(sighing) the contractor is looking after it. I have no involvement so sometimes they are not.... Day to day waste they use to burn; that is not good actually. But I didn't tell anything. Other thing is whatever the excess they have to send it out of the site, so that was the agreement".

Construction waste is hazardous and emissions from burning the waste can harm the environment as well as neighbouring surroundings. Clients lacking such a critical awareness with respect to the social, environmental and economic aspects, reflects the poor attitude pertaining to the sustainability in the construction industry. 


\section{CONCLUSIONS AND RECOMMENDATIONS}

In conclusion, the construction industry is still in the process of achieving sustainability through client intervention particularly with regard to the business processes related CSR. It was extracted from the study that the clients in the construction industry of Sri Lanka are primarily focusing on cost contrary to quality and durability of the outcome. Further, it was acknowledged from the analysis that clients who intended to sell their properties highly prioritized initial cost while clients who were to occupy the development considered sustainable approaches and quality to a certain extent based on their financial capacity. However, the client is not always at fault since it is not realistic to blindly invest money on a concept that they are clearly not aware of and have no considerable involvement. Hence, it was examined through investigation that consultants had to play a significant role in educating and convincing clients on such implementations. The clients revealed that they needed a proper presentation with reference to facts and figures in order to invest on any kind of approach that isn't conventional. Moreover, it was clarified that even the clients preferred short-term gains with contrast to long-term benefits.

Although it is practically not possible for a client to disregard cost and concentrate on sustainable approaches, it is recommended to absorb sustainability through CSR considering it as a moral obligation for inter-generational contemplation. It is not always expensive to be sustainable; designing wisely and conducting the business process in an ethical manner is a means of attaining stipulated goals. Fiscal and regulatory framework is a great source to encourage sustainability to be embraced by organisations and subsequently attempting to convince the client by emphasizing the merits and future potential for prospects.

Additionally, it was observed that the clients' main intention to initiate sustainable measures were to obtain government approvals and permits. This implies the importance and influence the government could impact. Thus, it is recommended to give concession or recognition to the clients who implement sustainability in their business process, which would further motivate other clients to embrace such concepts.

Further, the consultant's correspondence with the clients was identified to be a crucial factor in plotting the latter as a crucial avenue to promote CSR and achieve sustainability in the construction industry. It was clarified that the green concept is not practical in the view of the clients, but the actual reason identified is the poor persuasiveness by consultants. Therefore, it is proposed that clients should play a primary role in scanning and selecting a consultant renowned for enforcing a sustainable business process in the construction industry. This highlights the necessity to assess and evaluate the consultants based on a wide perception considering their ability to develop a cooperative project environment while establishing means to resolve conflicts and solve problems.

Majority of the clients appraised were involved in commercial and residential building construction and thus if those clients do not make an attempt to contribute on sustainability consistently, this would remain merely an illusion with respect to the lowprofile clients. It is suggested that if developers intend to sell their building and/or apartments, they must determine the selling cost by computing a figure inclusive of the cost for sustainable variables by acknowledging and educating the buyers on the benefits of sustainability in terms of the operational phase, maintenance, durability, intergenerational consideration and convincing same subsequently. This is defined as 
ethical trading where the client determines the added market value for sustainability concept and emphasise the advantages to convince customers on better quality via ethical purchasing. This is recommended to be implemented by providing weight to the business' core values with regard to its brand. Therefore, CSR shouldn't be simply an extension to the core business, but rather it should be a pivotal part of the business process.

Likewise, it was clarified through the study that if the clients are more considerate on the well-being of the labourers working at site and should the government introduce more benefits as well as providing encouragement and motivation, it will undoubtedly lead to a positive impact on the social and economic forces of sustainability. It was identified that the path for clients to promote CSR to achieve sustainability is through creating awareness, interest, their financial capability, experience, intergenerational concern and knowledge. Moreover, it is recommended to enact strict regulations to conserve the environment and its natural atmosphere by preventing the construction industry and its stakeholders from inflicting damage either in an upright or a commanding manner.

\section{ACKNOWLEDGEMENTS}

We wish to acknowledge all the interviewees for their participation and all other individuals who helped us compile this research.

\section{REFERENCES}

Abeysundara, U. G. Y., Babel, S., and Gheewala, S., 2009. A matrix in life cycle perspective for selecting sustainable materials for buildings in Sri Lanka. Building and Environment, 44(5), pp.997-1004.

Alshenqeeti, H., 2014. Interviewing as a data collection method: A critical review. English Linguistics Research, 3(1), p.39.

Ayuso, S., Ángel Rodríguez, M., García-Castro, R. and Ángel Ariño, M., 2011. Does stakeholder engagement promote sustainable innovation orientation?. Industrial Management \& Data Systems, 111(9), pp.1399-1417.

Bal, M., Bryde, D., Fearon, D. and Ochieng, E., 2013. Stakeholder engagement: Achieving sustainability in the construction sector. Sustainability, 5(2), pp.695-710.

Barthorpe, S., 2010. Implementing corporate social responsibility in the UK construction industry. Property Management, 28(1), pp.4-17.

Berger, I. E., Cunningham, P. H., and Drumwright, M. E., 2007. Mainstreaming corporate social responsibility: Developing markets for virtue. California Management Review, 49(4), pp.132-160.

Carroll, A.B., 1991. The pyramid of corporate social responsibility: Toward the moral management of organisational stakeholders. Business Horizons, 34(4), pp.39-48.

Creswell, J.W., Hanson, W.E., Clark Plano, V.L. and Morales, A., 2007. Qualitative research designs: Selection and implementation. The Counselling Psychologist, 35(2), pp.236-264.

Department of Census and Statistics, 2017. Sri Lanka Labour Force Survey - Annual Report 2017 [online]. Available from: http://www.statistics.gov.lk/samplesurvey/LFS_Annual\%20Report_2017_version2.pdf [Accessed 15 January 2019].

De Silva, N., Rajakaruna, R.W.D.W.C.A.B. and Bandara, K.A.T.N., 2008. Challenges faced by the construction industry in Sri Lanka: perspective of clients and contractors. Building Resilience, pp.158169.

Doody, O. and Bailey M. E (2016) Setting a research question, aim and objective. Nurse Researcher. 23(4), pp.19-23.

Dörnyei, Z., 2007. Research methods in applied linguistics: Quantitative, qualitative, and mixed methodologies. Oxford: Oxford University Press. 
Dyllick, T. and Hockerts, K., 2002. Beyond the business case for corporate sustainability. Business Strategy and the Environment, 11(2), pp.130-141.

Ebner, D. and Baumgartner, R.J., 2006. The relationship between sustainable development and corporate social responsibility. Corporate Responsibility Research Conference, 4(5.9), Queens University, Belfast Dublin.

Herremans, I.M. and Reid, R.E., 2002. Developing awareness of the sustainability concept. The Journal of Environmental Education, 34(1), pp.16-20.

Huang, C.F. and Lien, H.C., 2012. An empirical analysis of the influences of corporate social responsibility on organisational performance of Taiwan's construction industry: using corporate image as a mediator. Construction Management and Economics, 30(4), pp.263-275.

Jones, P., Comfort, D. and Hillier, D., 2006. Corporate social responsibility and the UK construction industry. Journal of Corporate Real Estate, 8(3), pp.134-150.

Kakabadse, N.K., Rozuel, C. and Lee-Davies, L., 2005. Corporate social responsibility and stakeholder approach: a conceptual review. International Journal of Business Governance and Ethics, 1(4), pp.277302.

Khalfan, M.M., McDermott, P., Vrijhoef, R. and Asad, S., 2005. The effect of procurement on the integration of the supply chain within the construction industry. Proceedings CIB Combining Forces, 1 , pp.14-25.

Kometa, S.T., Olomolaiye, P.O. and Harris, F.C., 1994. Attributes of UK construction clients influencing project consultants' performance. Construction Management and Economics, 12(5), pp.433-443.

Kothari, C.R., 2004. Research Methodology Methods and Techniques. $2^{\text {nd }}$ ed. New Delhi: New Age International Publishers.

Lester, S., 1999. An introduction to phenomenological research. Taunton UK, Stan Lester Developments.

Lim, E.H. and Ling, F.Y.Y., 2002. Model for predicting clients' contribution to project success. Engineering, Construction and Architectural Management, 9(5/6), pp.388-395.

Ling, F.Y.Y., Ofori, G. and Dulaimi, M.F., 2005. Targeting constraints and improving performance in Singapore construction. Combining Forces Advancing: Facilities Management and Construction through Innovation Series, 1, pp.61-72.

Murray, M. and Dainty, A., 2009. Corporate social responsibility in the construction industry. Abington: Taylor \& Francis.

O'Connor, J.T., Torres, N. and Woo, J., 2015. Overview of construction sustainability research products. 5th International/11th Construction Specialty Conference, pp.134:1-134:10.

Pitt, M., Tucker, M., Riley, M. and Longden, J., 2009. Towards sustainable construction: promotion and best practices. Construction innovation, 9(2), pp.201-224.

Polkinghorne, D. E., 1989. Phenomenological Research Methods. Existential-Phenomenological Perspectives in Psychology, pp.41-60.

Presley, A. and Meade, L., 2010. Benchmarking for sustainability: an application to the sustainable construction industry. Benchmarking: An International Journal, 17(3), pp.435-451.

Reve, T. and Levitt, R.E., 1984. Organisation and governance in construction. International Journal of Project Management, 2(1), pp.17-25.

Serpell, A., Kort, J. and Vera, S., 2012. Awareness, actions, drivers and barriers of sustainable construction in Chile. Technological and Economic Development of Economy, 19(2), pp.272-288.

Shen, L.Y., Tam, V.W., Tam, L. and Ji, Y.B., 2010. Project feasibility study: the key to successful implementation of sustainable and socially responsible construction management practice. Journal of Cleaner Production, 18(3), pp.254-259.

Somachandra, W.D.I.V., 2016. Critical Factors of Corporate Social Responsibility (CSR) in Sri Lankan Construction Industry. In Proceedings of $7^{\text {th }}$ International Conference on Sustainable Built Environment 2016 (ICSBE), Kandy, Sri Lanka, December 16-18, 2016. Department of Civil Engineering, University of Peradeniya, pp.01-09.

Spence, R. and Mulligan, H., 1995. Sustainable development and the construction industry. Habitat International, 19(3), pp.279-292. 
F.S. Rizvi and W.D.I.V. Somachandra

Zhao, Z.Y., Zhao, X.J., Davidson, K. and Zuo, J., 2012. A corporate social responsibility indicator system for construction enterprises. Journal of Cleaner Production, 29, pp.277-289. 